\title{
Treatment With Nonsteroidal Anti-Inflammatory Drugs Fails To Ameliorate Pathology In Cockatiels Experimentally Infected With Parrot Bornavirus-2
}

This article was published in the following Dove Press journal: Veterinary Medicine: Research and Reports

\author{
Paulina Escandon ${ }^{1,2}$ \\ J Jill Heatley (iD) ${ }^{1,3}$ \\ lan Tizard (D) 1,2 \\ Jianhua Guo ${ }^{1,2}$ \\ HL Shivaprasad (D) ${ }^{4}$ \\ Jeffrey MB Musser (iD) ${ }^{1,2}$ \\ 'Schubot Exotic Bird Health Center, \\ College of Veterinary Medicine, Texas \\ A\&M University, College Station, TX \\ 77843, USA; ${ }^{2}$ Department of Veterinary \\ Pathobiology, College of Veterinary \\ Medicine, Texas A\&M University, College \\ Station, TX 77843, USA; ${ }^{3}$ Department of \\ Small Animal Clinical Sciences, College of \\ Veterinary Medicine, Texas A\&M \\ University, College Station, TX 77843, \\ USA; ${ }^{4}$ California Animal Health and Food \\ Safety Laboratory System-Tulare, \\ University of California, Tulare, CA, USA
}

Correspondence: Jeffrey MB Musser Department of Veterinary Pathobiology, Texas A\&M University, Veterinary Medical Sciences Building, 400 Raymond Stotzer Pkwy \#4467, College Station, TX 77843, USA

Tel + I 9794589946

$\mathrm{Fax}+\mid 979458032$ |

Email Jmusser@cvm.tamu.edu
Purpose: Parrot bornavirus is the etiological agent of Parrot bornavirus syndrome, also referred to and comprising proventricular dilatation disease or PDD, macaw wasting disease, enteric ganglioneuritis and encephalitis, and avian ganglioneuritis. It has been suggested that nonsteroidal anti-inflammatory drugs may be able to ameliorate this disease. Therefore, this study investigated the effects of two commonly used nonsteroidal anti-inflammatory drugs, celecoxib and meloxicam, on cockatiels experimentally inoculated with Parrot bornavirus-2 (PaBV-2).

Materials and methods: Twenty-seven cockatiels were randomized into 3 groups of 9 birds, matched with respect to historical PaBV shedding, weight, and sex. The cockatiels were inoculated with cell culture-derived PaBV-2 by the intranasal and intramuscular routes. Beginning at 23 days post-inoculation, birds in each group received oral treatment once daily with placebo, meloxicam $(1.0 \mathrm{mg} / \mathrm{kg})$, or celecoxib $(10.0 \mathrm{mg} / \mathrm{kg})$.

Results: Within 33-79 days post-inoculation, 2 birds died and 6 birds were euthanized based on neurological or gastrointestinal signs consistent with Parrot bornavirus syndrome: 2 birds were euthanized in the placebo group, 1 bird died and 1 bird was euthanized in the meloxicam-treated group, and 1 bird died and 3 birds were euthanized in the celecoxibtreated group. Of these 8 birds, black intestinal contents were found upon necropsy in 2 birds of the meloxicam-treated group and 2 birds of the celecoxib-treated group. At day $173( \pm 2)$ post-inoculation, the remaining 19 birds were euthanized. Necropsy and histopathology showed lesions characteristic of Parrot bornavirus syndrome in 23 cockatiels. Histopathologic lesions were present in birds of all 3 groups. There was no statistical difference between the groups nor was there a statistical difference among the 3 treatment groups in the detection of PaBV RNA and PaBV nucleoprotein using RT-PCR and immunohistochemistry, respectively.

Conclusion: Meloxicam and celecoxib treatments do not appear to alter the clinical presentation, viral shedding, gross lesions, histopathology, or viral distribution. Treatment with NSAIDs may cause gastrointestinal toxicity in cockatiels experimentally inoculated with PaBV-2.

Keywords: meloxicam, celebrex, proventricular dilatation disease, parrot bornavirus syndrome, avian bornavirus

\section{Introduction}

Parrot bornaviruses 1-8 (PaBV- 1-8) are the causal agents of a progressive fatal avian neurologic syndrome referred to as Parrot bornavirus syndrome, a complex of clinical problems that can include proventricular dilatation disease or PDD, macaw wasting disease, enteric ganglioneuritis and encephalitis, avian ganglioneuritis, or neurological 
deficits. ${ }^{1-5}$ Parrot bornavirus syndrome primarily affects captive birds of the Psittacidae and Cacatuidae family, such as cockatoos, cockatiels, lovebirds, conures, parakeets (other than Budgerigars), and especially macaws, but has been diagnosed in over 80 bird species. $^{6-8}$ Tissue distribution of the virus following infection is extensive. Parrot Bornavirus and viral RNA are detected in the brain, eye, retinal nerve, spinal cord, heart, adrenal glands, kidneys, and intestines. ${ }^{9,10}$ The disease is characterized by infection of the central and peripheral nervous system and other organs with PaBV, leading to lymphoplasmacytic infiltration of those tissues, and culminating in nervous system disorders and gastrointestinal malfunctions. ${ }^{8-14}$

No effective treatment for PaBV infection or Parrot bornavirus syndrome currently exists. Experimentally, IFN- $\alpha$ inhibits virus infection and reduces viral load in quail cell culture ${ }^{15}$ and ribavirin inhibits transcription and reduces the viral load in cultured duck embryo fibroblasts. ${ }^{16,17}$ Symptomatic treatment and management are the only currently recommended therapies for Parrot bornavirus syndrome. ${ }^{7,18}$ Based on clinical and pathological signs of $\mathrm{PaBV}$ infection, disease may result from inflammatory reactions to the virus within the brain, nerves, and other tissues. ${ }^{10-12}$ Thus, nonsteroidal anti-inflammatory drugs (NSAIDs) and immunosuppressive drugs could inhibit or reduce the inflammation caused by PaBV infection and lessen the severity of the clinical disease. ${ }^{7,18}$

The use of NSAIDs is reported to reduce the severity of clinical signs in birds affected with PDD. ${ }^{7}$ Celecoxib and meloxicam are NSAIDs commonly used for the symptomatic treatment of birds diagnosed with Parrot bornavirus syndrome. ${ }^{18-21}$ However, meloxicam did not reduce the clinical signs in cockatiels experimentally infected with PaBV-4 and in fact may have exacerbated the disease progression. ${ }^{22}$

Due the discrepancies in reported outcomes and the limited controlled studies on the effectiveness of NSAIDs and dearth of research comparing celecoxib and meloxicam in treating PaBV infected birds, the objective of this study was therefore to evaluate the effects of celecoxib and meloxicam treatment on clinical signs, viral shedding, and pathology of cockatiels infected with PaBV-2. We hypothesized that NSAID administration will reduce the severity of disease in infected cockatiels.

\section{Materials And Methods}

\section{Parrot Bornavirus}

PaBV-2 was isolated from the brain of experimentally infected cockatiels (Nymphicus hollandicus). ${ }^{14}$ Virus for inoculation was grown as previously described. ${ }^{23}$ Briefly, duck embryo fibroblast cultures were inoculated with stock virus and maintained in Dulbecco's modified eagle medium (Gibco ${ }^{\circledR}$, Life Technologies Co., Thermo Fisher Scientific, Waltham, MA, USA) with $10 \%$ fetal bovine serum $\left(\mathrm{Gibco}^{\circledR}\right.$, Life Technologies Co) at $37^{\circ} \mathrm{C}$ in an atmosphere of $5 \% \mathrm{CO}_{2}$. After 3 days of incubation, cells were harvested, divided into $1.0 \mathrm{~mL}$ aliquots, and stored at $-80^{\circ} \mathrm{C}$. Virus was confirmed to be PaBV-2 by RNA extraction and RT-PCR analysis followed by sequence analysis of the PCR product, as described below. Birds were inoculated using a combined intranasal and intramuscular administration of infected cells containing $8 \times 10^{4}$ focus forming units of the virus.

\section{Nonsteroidal Anti-Inflammatory Drugs}

A suspension containing $1.0 \mathrm{mg} / \mathrm{mL}$ meloxicam was made by crushing three meloxicam $15.0 \mathrm{mg}$ tablets (Lupin, Pharmaceuticals, Inc. Baltimore, MD, USA) using a mortar and pestle, and dissolving the powder in $1 \mathrm{~mL}$ deionized water. Ten millilitre of Ora-Plus (Perrigro ${ }^{\circledR}$ Co., Dublin, Ireland) suspending vehicle was added, and then Ora-Sweet (Perrigro ${ }^{\circledR}$ Co.) was added to the suspension to obtain a final volume of $45.0 \mathrm{~mL}$. A suspension containing $10.0 \mathrm{mg} / \mathrm{mL}$ celecoxib was made by adding the contents of nine celecoxib $50.0 \mathrm{mg}$ capsules (Pfizer Inc., Mission, KS, USA) to $1.0 \mathrm{~mL}$ deionized water. Ten millilitre of OraPlus suspending vehicle was added, and then Ora-Sweet added to the suspension to obtain a final volume of 45.0 $\mathrm{mL}$. All solutions were stored at $4^{\circ} \mathrm{C}$ and prepared fresh every 30 days. Prior to administration, all solutions were warmed to room temperature.

\section{Animals}

Twenty-seven cockatiels (Nymphicus hollandicus), ranging from 79 to $145 \mathrm{~g}$ (mean $101 \mathrm{~g}$ ), were used. The birds were assessed as healthy by physical examination and medical history. The cockatiels were quarantined for 60 days, during which time each bird was tested three times over 4 weeks for psittacid herpesvirus (genotype 14), Chlamydia spp. and Macrorhabdus ornithogaster (avian gastric yeast). Birds needed to have all tests negative to be included in the study. The cockatiels were housed 14 or 13 birds per cage, with a light-dark cycle of $12 \mathrm{hrs}$ and a room temperature of $23.3( \pm 5.0)^{\circ} \mathrm{C}$, at the Schubot Exotic Bird Health Center aviary, Texas A\&M University. Birds were fed a 1/6 cup per bird of premium daily FruitBlend with natural fruit flavors $\left(\mathrm{ZuPreem}{ }^{\circledR}\right.$, 
Shawnee, KS, USA), and had access to tap water ad libitum. An animal use protocol detailing the experimental protocol was reviewed and approved by the Texas A\&M University Office of Research Compliance, complying with guidelines included in the National Research Council of the National Academies' publication Guide for the Care and Use of Laboratory Animals, 8th edition.

\section{Experimental Protocol}

Birds were matched with respect to historical shedding of $\mathrm{PaBV}$, weight, and sex, and randomly assigned into three groups of nine birds each: Group 1 birds (placebo) were inoculated with PaBV-2 and beginning 23 days post-inoculation were treated orally, once daily with only the delivery solution (water, Ora-plus, and Ora-Sweet). Group 2 birds (meloxicam treated) were inoculated with PaBV-2 and beginning 23 days post-inoculation were treated orally, once daily with $1.0 \mathrm{mg} / \mathrm{kg}$ meloxicam. Group 3 birds (celecoxib treated) were inoculated with PaBV-2 and beginning 23 days post-inoculation were treated orally, once daily with $10.0 \mathrm{mg} / \mathrm{kg}$ celecoxib. All treatments were administered prior to morning feeding. The dosage of drug administered was recalculated after each weekly weighing. The drug treatment administered to each group was unknown to the drug administrator/evaluator, assay technician, and pathologist until completion of the study.

Birds were observed daily for clinical signs and deviations from normal behavior: these included feather fluffing, bowed head, overly quiet, almond-shaped eyes, over-eating, lethargy, and reluctance to fly. Prior to inoculation, cloacal swabs were collected twice; weights and body condition scores (BCS) were assessed once. After viral inoculation, birds were weighed and BCS was assessed weekly; cloacal swabs were collected every third week and stored at $-80^{\circ} \mathrm{C}$ until assayed by RT-PCR. Body condition scores were determined by assessing the region of the keel and pectoral muscle. Body condition scores ranged from 1 to 5 , thin to obese, respectively. ${ }^{24} \mathrm{~A}$ bird was withdrawn from the study and euthanized if it met the following pre-established criteria: weight loss $>20 \%$ of the initial weight; BCS of 1 ; or as recommended by the attending veterinarian.

On day $173( \pm 2)$ following experimental inoculation [day $150( \pm 2)$ of NSAID treatment or placebo treatment], surviving birds were anesthetized with $5 \%$ isoflurane in $100 \%$ oxygen; weight, BCS, cloacal swab, and urine were collected. Urine was collected as previously described by Heatley et al. ${ }^{25}$ Immediately after sample collection while the bird was still in deep anesthesia, the bird was humanely killed by chamber exposure to $100 \% \mathrm{CO}_{2}$. A complete necropsy was performed immediately and gross lesions were recorded. Paired samples of heart, liver, feather follicle, spleen, crop, proventriculus, ventriculus, intestine, gonad, pancreas, adrenal gland, kidney, lung, spinal cord, brain, eye, aqueous humor, optic nerve, brachial plexus, and sciatic nerve were collected and stored at $-80^{\circ} \mathrm{C}$ for later analyses by RT-PCR. The remainder of each organ was placed in $10 \%$ neutral-buffered formalin for histologic examination and immunohistochemistry (IHC) testing.

\section{RT-PCR}

Tissue, urine, and cloacal swabs were tested for the presence of viral RNA by RT-PCR as previously described. ${ }^{23}$ All samples were tested in duplicate for both the matrix protein and phosphoprotein. Samples were considered negative for cycle threshold $\left(\mathrm{C}_{\mathrm{T}}\right) \geq 37.0$. If a sample was positive for only one of the two proteins, the sample was retested. Results were analyzed using the Sequence Detection System, Version 2.4.1 (SDS 2.4) software (Life Technologies, Thermo Fisher, Carlsbad, CA, USA).

\section{Histopathology \& Immunohistochemistry}

Tissue samples were fixed in 10\% neutral-buffered formalin, processed overnight, embedded in paraffin, sectioned at 4 $\mu \mathrm{m}$, stained with haematoxylin and eosin ( $\mathrm{H} \& \mathrm{E})$, and examined by light microscopy according to standard procedure. Immunohistochemistry, to demonstrate the presence of $\mathrm{PaBV}$ nucleoprotein, was performed on tissues obtained at necropsy according to previously described methods. ${ }^{26}$ The reviewing pathologist assigned a semiquantitative viral score to the tissue sample using the following ordinal scale: none detected (-), small quantity detected $(+)$, moderate quantity detected $(++)$, large quantities detected $(+++)$.

\section{Statistical Analysis}

The Gehan-Breslow method was used to analyze differences in survival between the treatment groups. Two-way repeated measures Analysis of Variance (ANOVA) was used to compare weight changes between the treatment groups and day over the experimental time course. The Kruskal-Wallis One Way ANOVA on ranks was used to ascertain differences in histological findings and IHC results. A $P \leq 0.05$ was considered statistically significant. Sigma Plot version 10.0.1 was used for performing all statistical analyses (Systat Software, Inc., San Jose, CA, USA). 


\section{Results}

\section{Clinical Observations}

Survival did not differ significantly between the 3 study groups (Figure 1). In the placebo group (group 1), 2 of 9 birds were euthanized prior to the end of the study on 54 and 61 days post-inoculation. In the meloxicam-treated group (group 2), 2 of 9 birds were euthanized or found dead on 33 and 79 days post-inoculation. In the celecoxib-treated group (group 3), 4 of 9 birds were euthanized or found dead on $37,43,45$, and 74 days post-inoculation. Of the 8 birds that died prior to study completion, 2 were found dead, one each in the meloxicam and the celecoxib-treated groups, while the remaining 6 showed neurological or gastrointestinal signs characteristic of PaBV infection (Table 1).

Body weights did not differ significantly between the study groups over the study period. Within each treatment group, significant daily differences in weight were noted. All groups had a reduction in weight on day 7 after treatment, with or without NSAID, was administered. Between 7 and 47 days, the body weights of the NSAID-treated groups were significantly lower than the weights prior to inoculation or the commencement of the NSAID treatment; however, from 54 days after treatment until study's end, there was no significant difference between their weight prior to inoculation

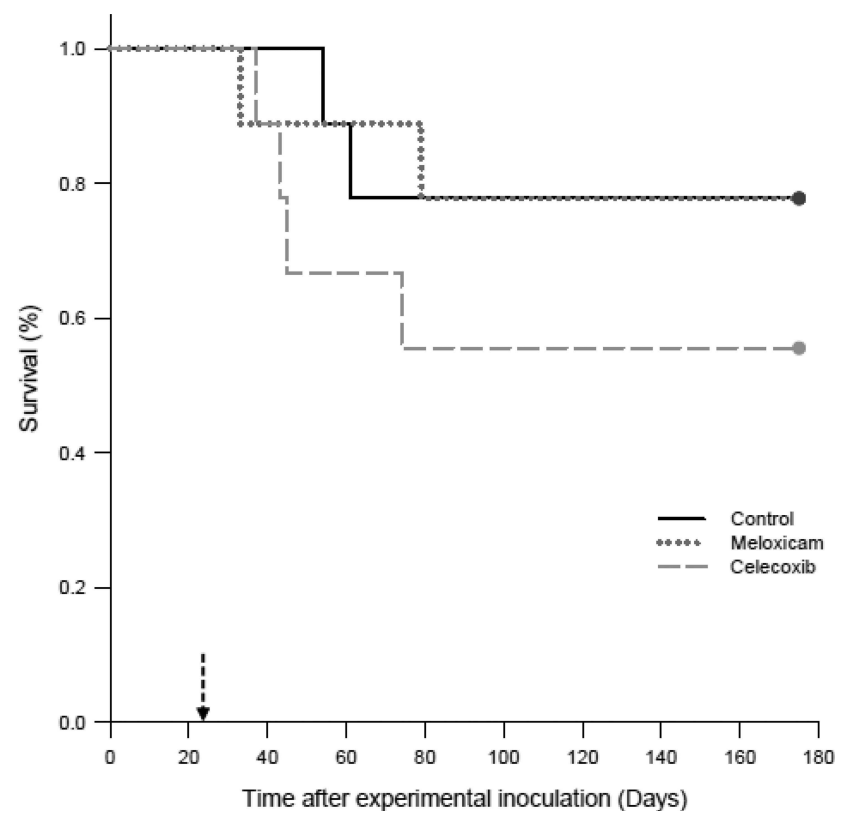

Figure I Survival analysis of cockatiels (Nymphicus hollandicus) inoculated with PaBV-2 and treated with either placebo, meloxicam $(1.0 \mathrm{mg} / \mathrm{kg})$, or celecoxib $(10.0 \mathrm{mg} / \mathrm{kg})$. Notes: The Gehan-Breslow statistic for survival curve was used to generate the survival analysis. Birds were experimentally inoculated with PaBV-2 on day 0 . On day 23 post-inoculation (dashed arrow), birds started once daily, oral administration with the following: placebo control group (solid black line), meloxicam (dotted grey line) and celecoxib (dashed grey line). or treatment. Body condition scores between or within the groups did not differ significantly during the study period.

Most birds that died or were euthanized early tended to have lost weight and BCS over the course of the study. A single bird from the meloxicam group was an exception. At the time of euthanasia, this bird had a greatly increased weight compared to other birds, but had a low BCS. Necropsy findings of a profoundly dilated crop and proventriculus that were full of feed were most likely the cause of the increased weight (Figure 2B).

\section{Detection Of PaBV RNA}

The results of viral RNA detection in cloacal swab samples are summarized in Table 2. Prior to experimental inoculation, cloacal swab testing for viral RNA was negative for all birds, with the exception of one cockatiel that had a positive cloacal swab on day -17 of inoculation, but was negative on days $-31,13$, and 20 post-inoculation. PaBV shedding was first detected 42 days post-inoculation in groups 2 and 3 . At study end, all birds that had not died or been euthanized early for humane concerns had positive cloacal swabs, with the exception of one bird in group 2, which was negative throughout the study period. The cumulative number of birds with positive cloacal swabs by the end of the study was $8 / 9,6 / 9$, and $7 /$ 9 in groups 1, 2, and 3, respectively.

At the study's end, viral RNA was detected in the midbrain, hindbrain, cerebellum, forebrain, kidney, and urine of all surviving birds, except for one. There was no significant difference in the amount of detectable viral RNA between the treatment groups.

\section{Necropsy And Histopathology}

The predominant gross abnormalities seen at necropsy were dilation of the crop and proventriculus and an enlarged, dilated heart with thin walls (Figure 2A-C). However, these abnormalities were not consistently present nor of consistent severity. Birds that were euthanized or died early in the study had more pronounced crop and proventricular dilatation than birds that survived until day $173( \pm 2)$ post-inoculation. Black intestinal contents were present in 2 birds in group 2 and 2 birds in group 3; these 4 birds had been euthanized prior to the study's endpoint (Figure 2B and C). Other abnormalities such as liver mottling, enlarged spleen, mild intestinal distension, and pale pancreas were occasionally noted, with no predilection for any group. Histopathological changes occurred in many tissues, but no significant differences in the severity of the lesions occurred based on group (Table 3). The lesions observed 
Table I Cockatiels Euthanized Or Found Dead Prior To Study's End

\begin{tabular}{|c|c|c|c|c|c|}
\hline Treatment & $\begin{array}{l}\text { Bird } \\
\text { ID }\end{array}$ & $\begin{array}{l}\text { Died Or } \\
\left.\text { Euthanized (Day }{ }^{\mathrm{a}}\right)\end{array}$ & BCS & $\begin{array}{l}\text { Weights } \\
\text { (gms) }\end{array}$ & Observations \\
\hline Placebo & $\begin{array}{l}1 \\
2\end{array}$ & $\begin{array}{l}54 \\
61\end{array}$ & $\begin{array}{l}3 \\
2\end{array}$ & $\begin{array}{l}95.0 \\
74.8\end{array}$ & $\begin{array}{l}\text { Loss of balance and flying into cage wall } \\
\text { Regurgitating with a distended crop }\end{array}$ \\
\hline Meloxicam & $\begin{array}{l}10 \\
11\end{array}$ & $\begin{array}{l}33 \\
79\end{array}$ & $\begin{array}{l}1 \\
2\end{array}$ & $\begin{array}{l}76.0 \\
117.6\end{array}$ & $\begin{array}{l}\text { Found dead } \\
\text { Regurgitation, enlarged crops, feather fluffing, head drooping and tilted, off } \\
\text { balanced, lethargic, spends most of the time on the cage floor }\end{array}$ \\
\hline Celecoxib & $\begin{array}{l}19 \\
20 \\
21 \\
22\end{array}$ & $\begin{array}{l}37 \\
43 \\
45 \\
74\end{array}$ & $\begin{array}{l}2 \\
2 \\
3 \\
1\end{array}$ & $\begin{array}{l}97.0 \\
74.5 \\
83.0 \\
64.0\end{array}$ & $\begin{array}{l}\text { Found dead } \\
\text { Eyes closed, unstable, head tilt, lethargic } \\
\text { Eyes closed, unstable, head tilt, lethargic } \\
\text { Enlarged crop, eyes closed, unstable, head tilt, lethargic, feces dark in color }\end{array}$ \\
\hline
\end{tabular}

Notes: ${ }^{a}$ Is the day post-inoculation.

included: lymphoplasmacytic myenteric ganglioneuritis in the crop, proventriculus, ventriculus and intestines; multifocal dilation of tubules/interstitial inflammation, fibrosis and/or mineralization, and scattered lymphoid nodule formation in the kidney; lymphoplasmacytic infiltration within the epicardial, myocardial, and/or Purkinje cells of the heart; and, lymphoplasmacytic perivascular cuffing in the central nervous system (Figure 3). Though infrequent, histopathological changes were also seen in the liver, pancreas, lung, spleen, optic nerves, and adrenal glands.

\section{Immunohistochemistry}

Distribution or amount of viral nucleoprotein did not differ statistically between the three groups (Table 4). Virus
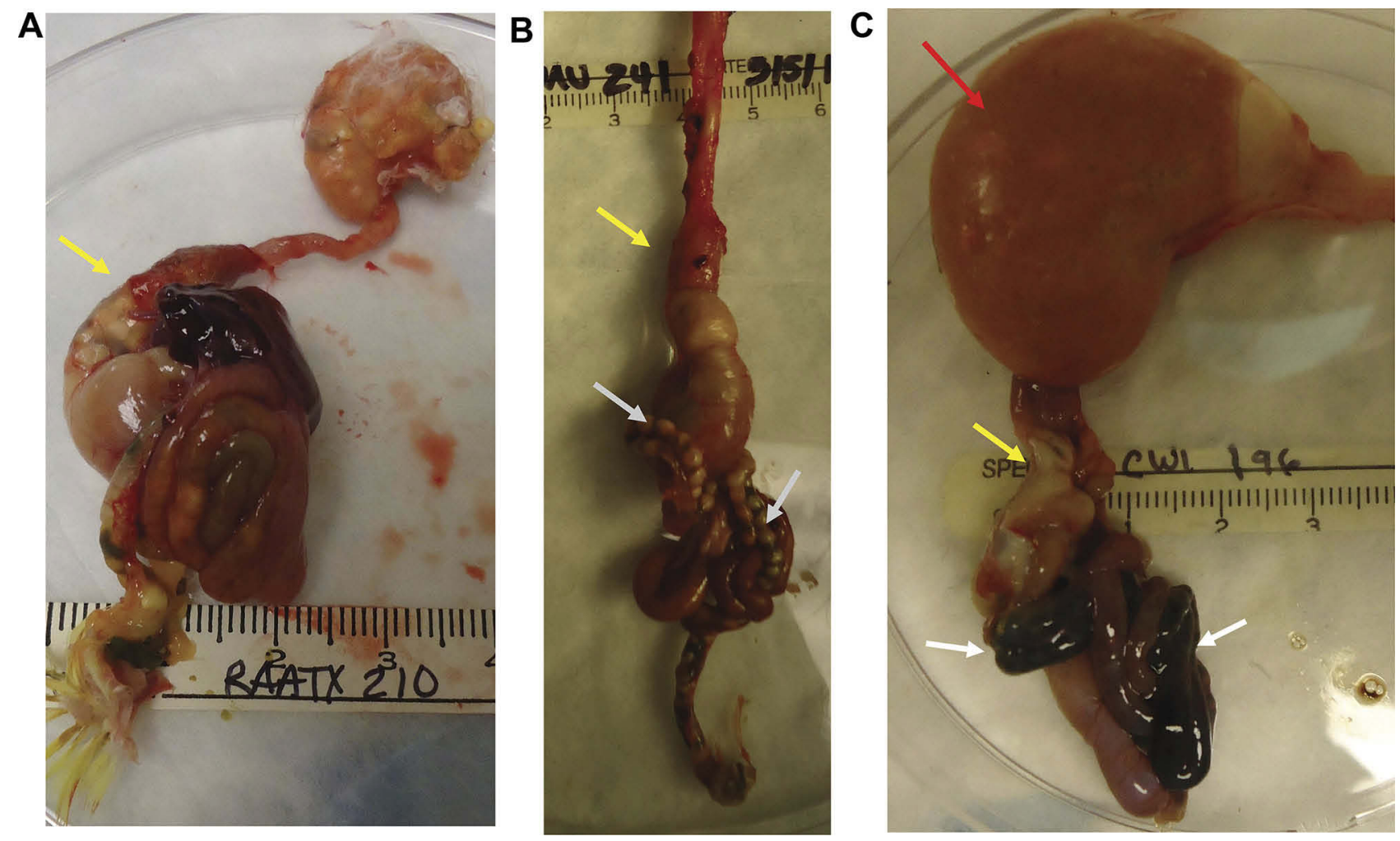

Figure 2 Gross necropsy findings in cockatiels (Nymphicus hollandicus) inoculated with PaBV-2 and treated with either placebo, meloxicam (I.0 mg/kg), or celecoxib (I0.0 $\mathrm{mg} / \mathrm{kg}$ ). (A) Bird 15, meloxicam-treated group: euthanized on day 173 post-inoculation. Moderate dilation of proventriculus (yellow arrow). (B) Bird 2I, celecoxib-treated group: euthanized on day 45 post-inoculation. Mild dilation of proventriculus (yellow arrow) with undigested seed present in the intestines (grey arrows). (C) Bird 22, celecoxib-treated group: euthanized on day 74 post-inoculation. Severe dilation of crop (red arrow), mild dilation of proventriculus (yellow arrow), and blacken intestinal content (grey arrows). 
Table 2 Detection Of Viral RNA In Cloaca Samples From Cockatiels (Nymphicus hollandicus) Inoculated With PaBV-2 And Treated With Placebo, Meloxicam (1.0 mg/kg), Or Celecoxib (10.0 mg/kg)

\begin{tabular}{|c|c|c|c|c|c|c|c|c|c|c|c|c|c|c|}
\hline \multirow[t]{2}{*}{ Treatment } & \multirow[t]{2}{*}{ Bird ID } & \multicolumn{13}{|c|}{ Day Post-Inoculation } \\
\hline & & $-31 /-17$ & 13 & 20 & $33 / 37$ & 42 & $43-61$ & 63 & $74 / 79$ & 84 & 103 & 125 & 146 & $173( \pm 2)$ \\
\hline Placebo & $\begin{array}{l}I^{\mathrm{a}} \\
2^{\mathrm{a}} \\
3 \\
4 \\
5 \\
6 \\
7 \\
8 \\
9\end{array}$ & $\begin{array}{l}-1- \\
-1- \\
-1- \\
-1- \\
-1- \\
-1- \\
-1- \\
-1- \\
-1-\end{array}$ & $\begin{array}{l}- \\
- \\
- \\
- \\
- \\
- \\
- \\
- \\
-\end{array}$ & $\begin{array}{l}- \\
- \\
- \\
- \\
- \\
- \\
- \\
- \\
-\end{array}$ & & $\begin{array}{l}- \\
- \\
- \\
- \\
- \\
- \\
- \\
- \\
-\end{array}$ & $\begin{array}{l}- \\
+\end{array}$ & $\begin{array}{l} \\
- \\
+ \\
+ \\
+ \\
+ \\
+ \\
-\end{array}$ & & $\begin{array}{l}+ \\
+ \\
+ \\
+ \\
+ \\
+\end{array}$ & $\begin{array}{l}+ \\
+ \\
+ \\
+ \\
+ \\
+ \\
+\end{array}$ & $\begin{array}{l}+ \\
+ \\
+ \\
+ \\
+ \\
+ \\
+\end{array}$ & $\begin{array}{l}+ \\
+ \\
+ \\
+ \\
+ \\
+\end{array}$ & $\begin{array}{l}+ \\
+ \\
+ \\
+ \\
+ \\
+ \\
+\end{array}$ \\
\hline Meloxicam & $\begin{array}{l}10^{\mathrm{a}} \\
11^{\mathrm{a}} \\
12 \\
13 \\
14 \\
15 \\
16 \\
17 \\
18\end{array}$ & $\begin{array}{l}-1- \\
-1- \\
-1- \\
-1- \\
-1- \\
-1- \\
-1- \\
-1+ \\
-1-\end{array}$ & $\begin{array}{l}- \\
- \\
- \\
- \\
- \\
- \\
- \\
- \\
-\end{array}$ & $\begin{array}{l}- \\
- \\
- \\
- \\
- \\
- \\
- \\
- \\
-\end{array}$ & - & $\begin{array}{l}- \\
- \\
- \\
- \\
- \\
- \\
+ \\
-\end{array}$ & & $\begin{array}{l}- \\
+ \\
- \\
+ \\
- \\
+ \\
+ \\
-\end{array}$ & - & $\begin{array}{l}+ \\
+ \\
+ \\
+ \\
+ \\
-\end{array}$ & $\begin{array}{l}+ \\
+ \\
+ \\
- \\
+ \\
+ \\
-\end{array}$ & $\begin{array}{l}+ \\
+ \\
+ \\
+ \\
+ \\
+ \\
-\end{array}$ & $\begin{array}{l}+ \\
+ \\
+ \\
- \\
+ \\
+ \\
-\end{array}$ & $\begin{array}{l}+ \\
+ \\
+ \\
+ \\
+ \\
+\end{array}$ \\
\hline Celecoxib & $\begin{array}{l}19^{\mathrm{a}} \\
20^{\mathrm{a}} \\
21^{\mathrm{a}} \\
22^{\mathrm{a}} \\
23 \\
24 \\
25 \\
26 \\
27\end{array}$ & $\begin{array}{l}-1- \\
-1- \\
-1- \\
-1- \\
-1- \\
-1- \\
-1- \\
-1- \\
-1-\end{array}$ & $\begin{array}{l}- \\
- \\
- \\
- \\
- \\
- \\
- \\
- \\
-\end{array}$ & $\begin{array}{l}- \\
- \\
- \\
- \\
- \\
- \\
- \\
- \\
-\end{array}$ & - & $\begin{array}{l}- \\
+ \\
+ \\
- \\
+ \\
- \\
+ \\
-\end{array}$ & - & $\begin{array}{l}- \\
+ \\
+ \\
- \\
+ \\
+\end{array}$ & + & $\begin{array}{l}+ \\
+ \\
+ \\
+ \\
+\end{array}$ & $\begin{array}{l}+ \\
+ \\
+ \\
+ \\
+\end{array}$ & $\begin{array}{l}+ \\
+ \\
+ \\
+ \\
+\end{array}$ & $\begin{array}{l}- \\
+ \\
+ \\
+ \\
+\end{array}$ & $\begin{array}{l}+ \\
+ \\
+ \\
+ \\
+\end{array}$ \\
\hline
\end{tabular}

Notes: RT-PCR testing identified PaBV matrix and phosphoprotein RNA. -Negative (cycle threshold $\geq 37.0$ ); +Positive detection for viral RNA; ${ }^{2}$ Euthanized prior to study's endpoint of $173( \pm 2)$ days post-inoculation.

(PABV-2) was predominantly detected in the brain, heart, gastrointestinal tract and kidneys but also detected in liver, pancreas, lung, spleen, adrenal optic nerve, uropygial gland, cloaca, gonads, and skin/feather follicles. Skeletal muscle was the only tissue consistently negative for the virus. No virus was detected in any tissues of four birds: one in group 1, two in group 2, and one in group 3.

\section{Discussion}

Oral administration of meloxicam, $1.0 \mathrm{mg} / \mathrm{kg}$, or celecoxib, $10.0 \mathrm{mg} / \mathrm{kg}$, once daily for 150 days failed to show differences in the clinical presentation, viral shedding, gross lesions, viral distribution, nor histopathology in cockatiels experimentally inoculated with PaBV-2 when compared to untreated birds. These results agree with previously published experimental study on meloxicam usage, ${ }^{22}$ but conflict with reports on the treatment of clinically affected birds. ${ }^{19-21}$ Bird species differences, viral genotype differences, and evaluation criteria may account for the lack of agreement between our studies and previous reports on clinical cases.

In this study, 4 cockatiels treated with NSAIDs had black intestinal material that may have been autolyzed blood, and all 4 were euthanized after 10 to 56 days of NSAID treatment. In a prior study that treated $\mathrm{PaBV}$ inoculated cockatiels with meloxicam, 1 bird had blood-filled, blackened intestine, 


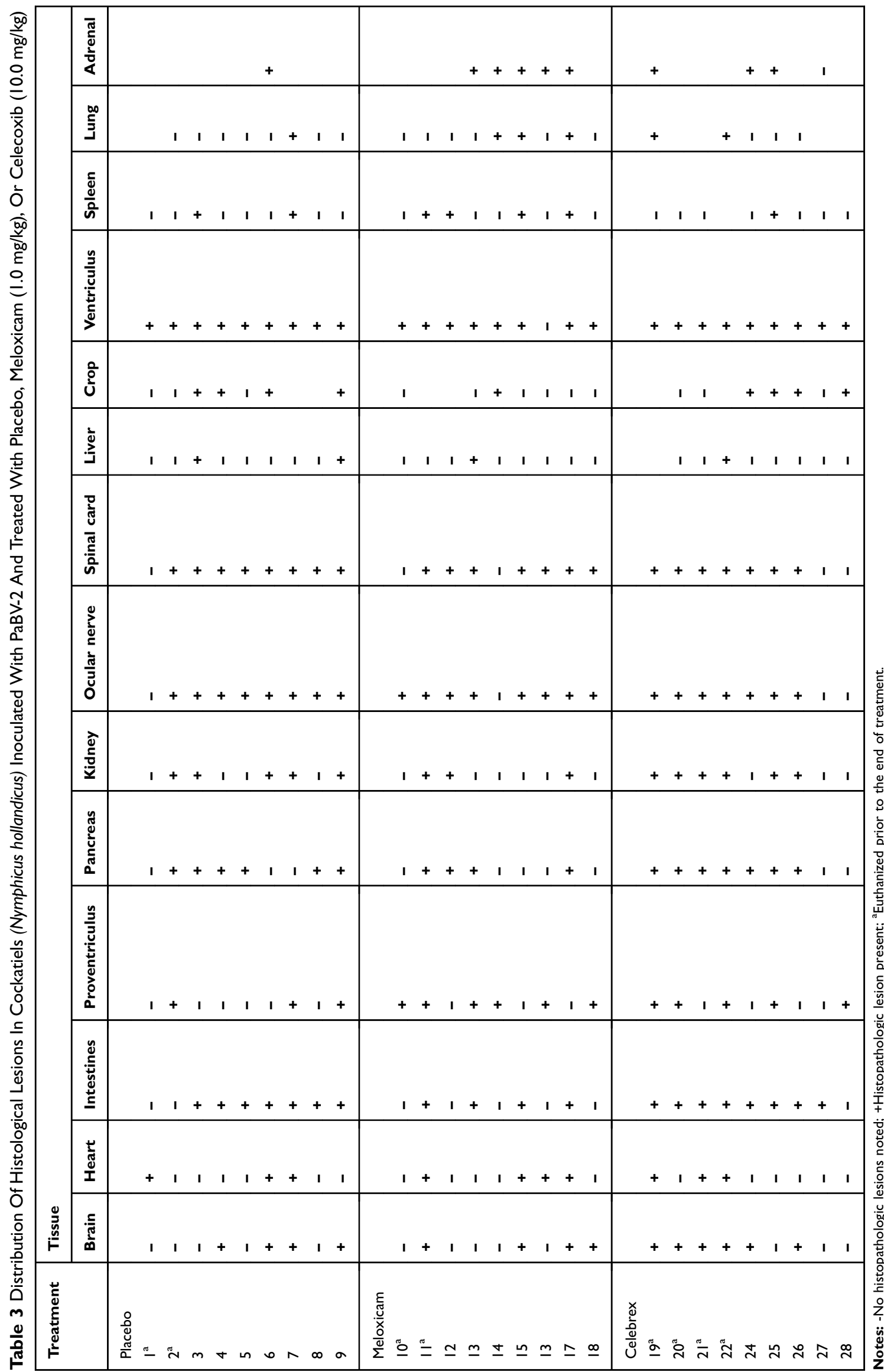



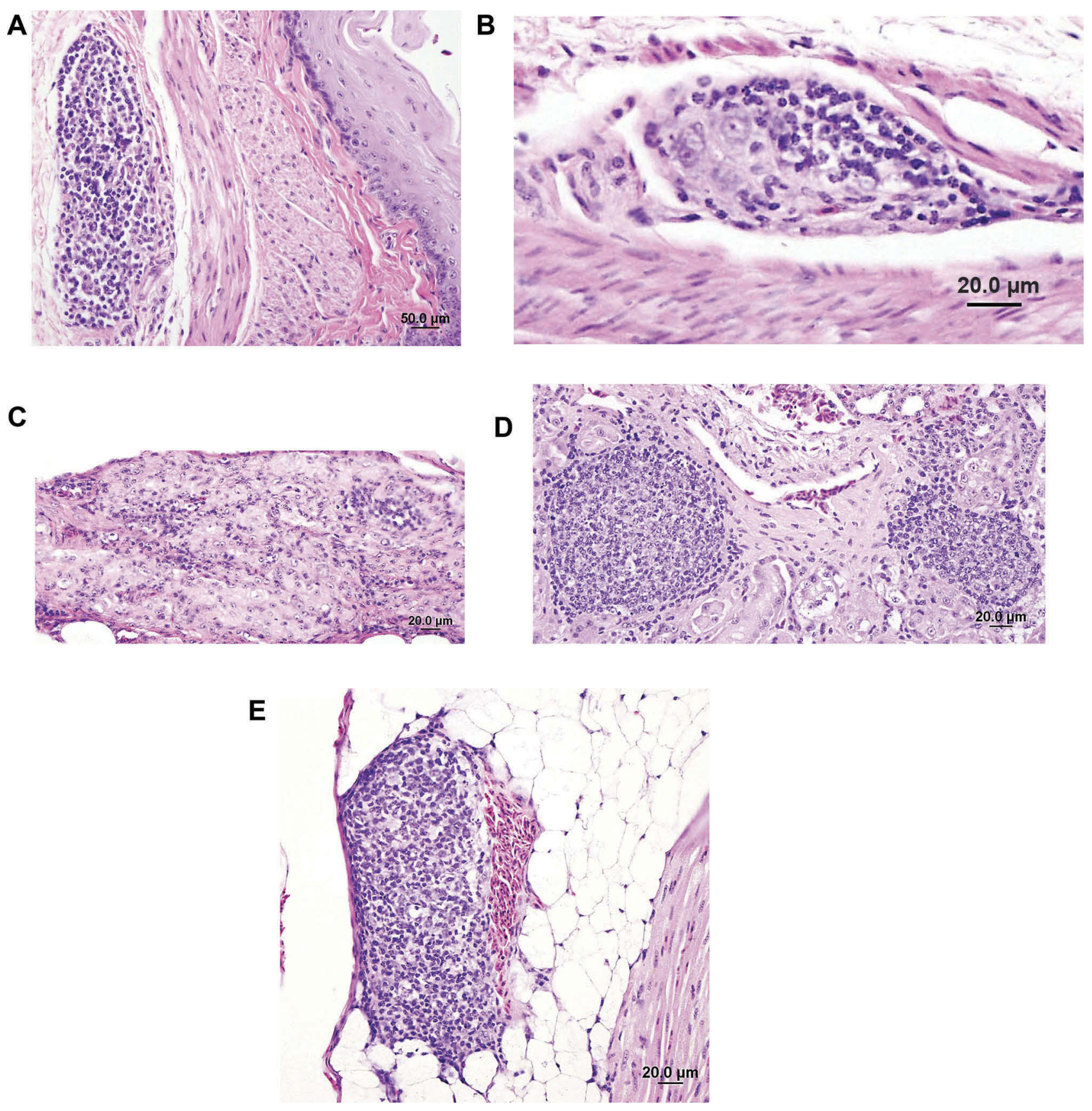

Figure 3 Histologic findings in cockatiels (Nymphicus hollandicus) inoculated with PaBV-2 and treated with either placebo, meloxicam ( $1.0 \mathrm{mg} / \mathrm{kg}$ ), or celecoxib (I0.0 mg/kg). (A) Lymphoplasmacytic infiltration of serosal ganglia of the crop. Bird 3, placebo, euthanized $173( \pm 2)$ days post-inoculation. (B) Moderate lymphoplasmacytic infiltration of subserosal ganglia in the proventriculus. Bird 9, placebo, euthanized $173( \pm 2)$ days post-inoculation. (C) Moderate lymphoplasmacytic infiltration of subserosal ganglia in the ventriculus. Bird 17, meloxicam treated, euthanized $173( \pm 2)$ post-inoculation. (D) Lymphocytic infiltration in the interstitium of kidney with formation of a lymphoid nodule. Bird 3, placebo, euthanized $173( \pm 2)$ days post-inoculation. (E) Lymphoplasmacytic infiltration in the epicardial ganglia of the heart. Bird 25, celecoxib treated, euthanized I73 $( \pm 2)$ days post-inoculation.

while another bird had black material that may have been autolyzed blood in its intestines. ${ }^{22}$ In mammals, gastrointestinal abnormalities, such as ulcers and bleeding, and renal necrosis due to ischemia are major features of NSAID toxicity; however, these have not been reported as major side effects of NSAID use in birds. ${ }^{27-35}$ The combined effect of
PaBV induced pathological changes and NSAID treatment may exacerbate gastrointestinal irritation and toxicity of the NSAID and may increase the risk for gastrointestinal bleeding.

The administration of NSAIDs to birds infected with PaBV did not affect their weight nor BCS. Birds that 
Table 4 Tissue Distribution And Relative Amount Of PaBV Nucleoprotein (N-protein) As Detected By Immunohistochemistry

\begin{tabular}{|c|c|c|c|c|c|c|c|c|c|c|c|}
\hline \multirow[t]{2}{*}{ Treatment } & \multirow[t]{2}{*}{ Bird ID } & \multicolumn{10}{|c|}{ Tissue } \\
\hline & & Brain & Heart & Liver & Intestine & Crop & Proventriculus & Ventriculus & Pancreas & Kidney & Lung \\
\hline \multirow[t]{10}{*}{ placebo } & & & & & & & & & & & \\
\hline & $\mathrm{I}^{\mathrm{a}}$ & - & & & & & - & & & & \\
\hline & $2^{\mathrm{a}}$ & +++ & & & & & - & & & & \\
\hline & 3 & +++ & ++ & - & +++ & ++ & +++ & +++ & +++ & ++ & + \\
\hline & 4 & +++ & & & ++ & ++ & +++ & +++ & +++ & ++ & \\
\hline & 5 & ++ & & & ++ & ++ & ++ & ++ & & & + \\
\hline & 6 & +++ & +++ & & ++ & ++ & ++ & ++ & - & + & \\
\hline & 7 & +++ & +++ & + & ++ & ++ & ++ & ++ & + & +++ & + \\
\hline & 8 & + & + & - & ++ & ++ & +++ & +++ & +++ & ++ & + \\
\hline & 9 & +++ & ++ & + & +++ & + & +++ & +++ & +++ & - & + \\
\hline \multirow[t]{10}{*}{ Meloxicam } & & & & & & & & & & & \\
\hline & $10^{\mathrm{a}}$ & - & & & & & - & & & & \\
\hline & $11^{\mathrm{a}}$ & +++ & & & & & - & & & & \\
\hline & 12 & ++ & & - & ++ & + & ++ & ++ & & & - \\
\hline & 13 & ++ & & - & +++ & + & ++ & ++ & ++ & ++ & - \\
\hline & 14 & +++ & ++ & ++ & ++ & + & ++ & ++ & ++ & +++ & ++ \\
\hline & 15 & +++ & & & - & - & + & + & - & & \\
\hline & 16 & +++ & & & ++ & + & ++ & ++ & - & - & \\
\hline & 17 & +++ & ++ & ++ & ++ & + & ++ & ++ & & ++ & ++ \\
\hline & 18 & - & & & - & - & - & - & - & & \\
\hline \multirow[t]{10}{*}{ Celecoxib } & & & & & & & & & & & \\
\hline & $19^{\mathrm{a}}$ & + & & & & & - & & & & \\
\hline & $20^{\mathrm{a}}$ & - & & & & & - & & & & \\
\hline & $21^{\mathrm{a}}$ & ++ & & & & & - & & & & \\
\hline & $22^{\mathrm{a}}$ & +++ & & & & & ++ & & & & \\
\hline & 23 & +++ & & - & ++ & + & ++ & ++ & ++ & +++ & + \\
\hline & 24 & ++ & & ++ & ++ & ++ & +++ & +++ & ++ & +++ & + \\
\hline & 25 & +++ & ++ & & ++ & ++ & +++ & +++ & ++ & ++ & ++ \\
\hline & 26 & +++ & & & ++ & ++ & ++ & ++ & & & ++ \\
\hline & 27 & +++ & & ++ & ++ & + & + & + & ++ & +++ & \\
\hline
\end{tabular}

Notes: -No PaBV-2 N-protein antigen detected; +Mild amount of PaBV-2 N-protein antigen detected; ++Moderate amount of PaBV-2 N-protein antigen detected; +++Large amount of PaBV-2 N-protein antigen detected; ${ }^{\text {E} E u t h a n i z e d ~ p r i o r ~ t o ~ t h e ~ e n d ~ o f ~ t r e a t m e n t . ~}$

displayed severe clinical signs and either were removed early or died, had decreased weight and BCS. This is consistent with the gastrointestinal dysfunction that leads to starvation in the birds. ${ }^{7,14,22,36}$ It is interesting to note that while most birds infected with PaBV decreased in weight, one bird in the meloxicam group had gained weight at the time of its removal from the study. Upon necropsy, the crop and proventriculus were distended with feed. Presumably, the weight gain was due to the proventricular contents. This reinforces that bird body weight alone should not be used to assess disease progression or severity.

Survival and early removal of the birds from the study were not statistically different between the groups; however, the number of birds with clinical conditions warranting early removal was twice as high in the celecoxib-treated group as compared to the meloxicamtreated or placebo group (Figure 1). In addition to the NSAIDs having no apparent effect on overall mortality, the time at which cockatiels started to show clinical signs and had to be removed early (33-79 days postPaBV inoculation) was not affected by NSAID treatment and was consistent with the time period seen in other studies of PaBV-2 experimentally inoculated birds. ${ }^{3,9,14,22,36,37}$

Gross pathology showed no significant difference between the three treatment groups and all groups had clinical presentations indicative of Parrot bornavirus 
syndrome, with a dilated proventriculus being most represented, as described in the literature. ${ }^{3,9,14,22,36,37}$ NSAID treatment in cockatiels inoculated with PaBV-2 was expected to decrease lesion distribution and tissue inflammatory response; however, in this study treatment lacked any significant impact.

Shedding of PaBV-2 was not affected by the administration of NSAIDs. In fact, treated birds tended to shed earlier than the placebo group, though there was no significant difference. Shedding was first detected on day 42 post-inoculation and became more consistent by day 63 post-inoculation, a time period that corresponded with previous work in our lab. At the end of the study, only one bird had not shed virus. Previous research has shown that there is not a $100 \%$ correlation between histopathology and virus detection between and among tissues and fluids. ${ }^{25,38}$

One bird in the meloxicam-treated group was negative for the presence of PaBV by RT-PCR and IHC throughout the study. However, at necropsy, its proventriculus was dilated and contained undigested seed. Histopathology showed perivascular cuffing with increased glial cells in the brain and lymph nodules in the mucosa, ganglia, and serosa of the ventriculus. Tissues may be negative for viral antigens by IHC but the animal can still have a subclinical or asymptomatic infection. ${ }^{38}$ Cryptosporidium was identified in the proventriculus of this bird which may have been a factor in causing some of these lesions. ${ }^{39}$

\section{Conclusion}

The administration of meloxicam or celecoxib failed to alter the progression or severity of clinical signs, gross or histopathological changes, viral shedding, or distribution of viral RNA in cockatiels infected with PaBV-2. Caution should be stressed when prescribing NSAIDs in birds with gastrointestinal dysfunction, such as may occur with $\mathrm{PaBV}$ infection, due to the potential for gastrointestinal irritation, bleeding, or other unwanted side effects of NSAIDs.

\section{Acknowledgments}

The authors thank Debra Turner and Dr. Jordan Gentry for technical assistance. Supported in part by the Schubot Exotic Bird Health Center. The open access publishing fees for this article have been covered by the Texas A\&M University Open Access to Knowledge Fund
(OAKFund), supported by the University Libraries and the Office of the Vice President for Research.

\section{Disclosure}

All authors declare no conflicts of interest relevant to the research performed.

\section{References}

1. Honkavuori KS, Shivaprasad HL, Williams BL, et al. Novel bornavirus in psittacine birds with proventricular dilatation disease. Emerg Infec Dis. 2008;14(12):1883-1886. doi:10.3201/eid1412.080984

2. Kistler AL, Gancz A, Clubb S, et al. Recovery of divergent avian bornaviruses from cases of proventricular dilatation disease: identification of a candidate etiologic agent. Virol J. 2008;5:88-102. doi: $10.1186 / 1743-422 \mathrm{X}-5-88$

3. Gray P, Hoppes S, Suchodolski P, et al. Use of avian bornavirus isolated to induce proventricular dilatation disease in conures. Emerg Infec Dis. 2010;16(3):473-479. doi:10.3201/eid1603.091257

4. Kuhn JH, Dürrwald R, Bào Y, et al. Taxonomic reorganization of the family Bornaviridae. Arch Virol. 2015;160(2):621-632. doi:10.1007/ s00705-014-2276-z

5. Philadelpho NA, Rubbenstroth D, Guimaraes MB, et al. Survey of bornaviruses in pet psittacines in Brazil reveals a novel parrot bornavirus. Vet Micro. 2014;174(3-4):584-590. doi:10.1016/j.vetmic.2014.10.020

6. Doneley RJT, Miller RI, Fanning TE. Proventricular dilatation disease: an emerging exotic disease of parrots in Australia. Aust Vet J. 2007;85(3):119-123. doi:10.1111/j.1751-0813.2007.00109.x

7. Gancz AY, Clubb S, Shivaprasad HL, et al. Advanced diagnostic approaches and current management of proventricular dilatation disease. Vet Clin North Am Exot Anim Pract. 2010;13(3):471-494. doi:10.1016/j.cvex.2010.05.004

8. Hoppes S, Gray PL, Payne S, et al. The isolation, pathogenesis, diagnosis, transmission, and control of avian bornavirus and proventricular dilatation disease. Vet Clin North Am Exot Anim Pract. 2010;13(3):495-508. doi:10.1016/j.cvex.2010.05.014

9. Piepenbring AK, Enderlein D, Herzog S, et al. Pathogenesis of avian bornavirus in experimentally infected cockatiels. Emerg Infect Dis. 2012;18(2):234-241. doi:10.3201/eid1802.111525

10. Leal de Araujo J, Rech RR, Heatley JJ, et al. From nerves to brain to gastrointestinal tract: A time-based study of parrot bornavirus 2 (PaBV-2) pathogenesis in cockatiels (Nymphicus hollandicus). PLoS One. 2017;12(11):e0187797. doi:10.1371/journal.pone.0187797

11. Ouyang N, Storts R, Tian Y, et al. Histopathology and the detection of avian bornavirus in the nervous system of birds diagnosed with proventricular dilatation disease. Avian Pathol. 2009;38(5):393-401. doi:10.1080/03079450903191036

12. Shivaprasad HL, Barr BC, Woos LW, et al. Spectrum of lesions (Pathology) of proventricular dilatation syndrome. Proc Annu Conf Assoc Avian Vet. 1995;505-506.

13. Berthane Y, Smith DA, Newman S, et al. Peripheral neuritis in psittacine birds with proventricular dilatation disease. Avian Pathol. 2001;30(5):563-570. doi:10.1080/03079450120078770

14. Mirhosseini N, Gray PL, Hoppes S, et al. Proventricular dilatation disease in cockatiels (Nymphicus hollandicus) after infection with a genotype 2 avian bornavirus. J Avian Med Surg. 2011;25(3):199-204. doi:10.1647/2010-030.1

15. Reuter A, Ackermann A, Kothlow S, et al. Avian bornaviruses escape recognition by the innate immune system. Viruses. 2010;2(4):927938. doi: $10.3390 / \mathrm{v} 2040927$

16. Escandon P, Heatley JJ, Kranz JB, et al. Effects of ribavirin on avian bornavirus in duck embryonic fibroblast cell culture. Proc ICARE Paris. 2015. 
17. Musser JMB, Heatley JJ, Koinis AV, et al. Ribavirin inhibits parrot bornavirus 4 replication in cell culture. PLoS One. 2015;10(7): e0134080. doi:10.1371/journal.pone.0134080

18. Hoppes S, Tizard I, Shivaprasad HL. Avian Bornavirus and proventricular dilatation disease. diagnostics, pathology, prevalence, and control. Vet Clin Exot Anim. 2013;16(2):339-355. doi:10.1016/j. cvex.2013.01.004

19. Dalhausen B, Aldred S, Colaizzi E, et al. Resolution of the clinical proventricular dilatation disease by cyclooxygenase 2 inhibition. Proc Annu Conf Assoc Avian Vet. 2002;9-12.

20. Clubb SL. Clinical management of psittacine birds affected with proventricular dilatation disease. Proc Annu Conf Assoc Avian Vet. 2006;85-90.

21. Keller DL, Honkavuori KS, Briese T, et al. Proventricular dilatation disease associated with avian bornavirus in a scarlet macaw (Ara Macao). J Vet Diagn Invest. 2010;22(6):961-965. doi:10.1177/ 104063871002200619

22. Hoppes S, Heatley JJ, Guo JH, et al. Meloxicam treatment in cockatiels (Nymphicus hollandicus) infected with avian bornavirus. J Exot Pet Med. 2013;22(3):275-279. doi:10.1053/j.jepm.2013. 08.014

23. Guo JH, Payne S, Zhang S, et al. Avian bornaviruses: diagnosis, isolation, and genotyping. Curr Protoc Microbiol. 2014;supplement 34:15i.1-15i.1.33. doi:10.1002/9780471729259.mc15i01s34.

24. Tully TN, Dorrestein GM, Jones AK. Handbook of Avian Medicine. 2nd ed. Philadelphia: Saunders/Elsevier; 2009.

25. Heatley JJ, Villalobos AR. Avian bornavirus in the urine of infected birds. Vet Med Res Rep. 2012;3:19-23. doi:10.2147/VMRR.s31336

26. Weissenböck H, Sekulin K, Bakonyi T, et al. Novel avian bornavirus in a nonpsittacine species (Canary; Serinus canaria) with enteric ganglioneuritis and encephalitis. J Virol. 2009;83(21):11367-11371. doi:10.1128/JVI.01343-09

27. Swarup D, Patra RC, Prakash V, et al. Safety of meloxicam to critically endangered Gyps vultures and other scavenging birds in India. Anim Conserv. 2007;10(2):192-198. doi:10.1111/j.14691795.2006.00086.x

28. Pereira ME, Werther K. Evaluation of the renal effects of flunixin meglumine, ketoprofen and meloxicam in budgerigars (Melopsittacus undulatus). Vet Res. 2007;160(24):844-846. doi:10.1136/ vr. 160.24.844

29. Desmarchelier M, Troncy E, Fitzgerald G, et al. Analgesic effects of meloxicam administration on postoperative orthopedic pain in domestic pigeons (Columba livia). Am J Vet Res. 2012;73(3):361367. doi:10.2460/ajvr.73.3.361
30. Musser JMB, Heatley JJ, Phalen DN. Pharmacokinetics after intravenous administration of flunixin meglumine in budgerigars (Melopsittacus undulates) and Patagonian conures (Cyanoliseus patagonus). J Am Vet Med Assoc. 2013;242(2):2005-2208. doi:10.2460/ javma.242.2.205

31. Molter CM, Court MH, Cole GA, et al. Pharmacokinetics of meloxicam after intravenous, intramuscular, and oral administration of a single dose to Hispaniolan Amazon parrots (Amazona ventralis). Am $J$ Vet Res. 2013;74(3):375-380. doi:10.2460/ajvr.74.3.375

32. Montesinos A, Ardiaca M, Juan-Sallés C, et al. Effects of meloxicam on hematologic and plasma biochemical analyte values and results of histologic examination of kidney biopsy specimens of African grey parrots (Psittacus erithacus). J Avian Med Surg. 2015;29(1):1-8. doi:10.1647/2013-056

33. Montesinos A, Ardiaca M, Gilabert JA, et al. Pharmacokinetics of meloxicam after intravenous, intramuscular and oral administration of a signal dose of African grey parrots (Psittacus erithacus). J Vet Pharmacol Ther. 2017;40(3):279-284. doi:10.1111/jvp.12350

34. Dhondt L, Devreese M, Croubels S, et al. Comparative population pharmacokinetics and absolute oral bioavailability of COX-2 selective inhibitors celecoxib, mavacoxib and meloxicam in cockatiels (Nymphicus hollandicus). Sci Rep. 2017;7(1):12043. doi:10.1038/s41598-01712159-z

35. Dijkstra B, Guzman DSM, Gustavsen K, et al. Renal, gastrointestinal, and hemostatic effects of oral administration of meloxicam to Hispaniolan Amazon parrots (Amazona ventralis). Am J Vet Res. 2015;76(4):308-317. doi:10.2460/ajvr.76.4.308

36. Payne S, Shivaprasad HL, Mirhosseini N, et al. Unusual and severe lesions of proventricular dilatation disease in cockatiels (Nymphicus hollandicus) acting as healthy carriers of avian bornavirus (ABV) and subsequently infected with a virulent strain of ABV. Avian Pathol. 2011;40(1):15-22. doi:10.1080/03079457.2010.536978

37. Gancz AY, Kistler AL, Greninger AL, et al. Experimental induction of proventricular dilatation disease in cockatiels (Nymphicus hollandicus) inoculated with brain homogenates containing avian bornavirus 4. Virol J. 2009;6:100. doi:10.1186/1743-422X-6-100

38. Raghav R, Taylor M, DeLay J, et al. Avian bornavirus is present in any tissues of psittacine birds with histopathologic evidence of proventricular dilatation disease. J Vet Diagn Invest. 2010;22(4):495508. doi:10.1177/104063871002200402

39. Ravich ML, Reavill DR, Hess L, et al. Gastrointestinal cryptosporidiosis in captive psittacine birds in the United States: a case review. J Avian Med Surg. 2014;28(4):297-303. doi:10.1647/1082-6742-28.4.297

\section{Publish your work in this journal}

Veterinary Medicine: Research and Reports is an international, peerreviewed, open access journal publishing original research, case reports, editorials, reviews and commentaries on all areas of veterinary medicine. The manuscript management system is completely online and includes a very quick and fair peer-review system. Visit http://www.dovepress.com/testimonials.php to read real quotes from published authors. 